\title{
Methodological issues in the assessment of sustained performance
}

\author{
BEN B. MORGAN, JR., and ELIZABETH W. PITTS \\ Old Dominion University, Norfolk, Virginia
}

\begin{abstract}
In both military and industrial work settings, it has become desirable, and in many instances necessary, to require sustained performance beyond the apparently optimal 8-h workday. Research in this area may be viewed historically as having been focused in three major areas: (1) determining appropriate methodologies for measuring sustained performance, (2) investigating factors that influence sustained performance, and (3) searching for ways to enhance performance during sustained operations. On the basis of discussions held in Toronto in August 1984, observations are drawn and recommendations are made concerning the directions and content of future research.
\end{abstract}

In their review of the effects of temporal factors in performance and productivity, Alluisi and Morgan (1982) concluded that "the findings are so consistent as to be close to compelling in terms of showing that what has become the typical, customary, even standard 8-h workday, 5-day/40-h workweek is optimum relative to longer hours of work" (p. 140). Among the studies cited in support of this conclusion are the results of an extensive survey of industrial production in 34 plants during World War II (Kossoris \& Kohler, 1947). These data indicate that increases in the length of the workday beyond the standard 8-h duration result in lower productivity and higher absenteeism and accident rates.

There are many situations in which it is desirable, or necessary, to increase the duration of sustained work activity beyond the apparently optimal 8-h duration. For example, recent trends in work scheduling have resulted in a rather widespread adoption of the 4-day/40-h workweek (see Glickman \& Brown, 1974). In addition, as clearly evidenced by papers contained in this section, ${ }^{1}$ there is a continuing interest in adopting 12-h industrial shifts as well as extending military performance requirements through several days of sustained operations. The papers published here provide many interesting findings that are applicable to the problems of sustaining work hours. A closer examination also provides a number of insights into the methodological issues that confront researchers in this area. Our purpose is to review the papers presented at the American Psychological Association (APA) symposium on "Sustaining Work Hours Without Decrements in Productivity" and the Canadian Defence Civil Institute of Environmental Medicine (DCIEM) workshop on

Based in part upon a presentation made by the senior author as discussant in C. E. Englund and G. P. Krueger (co-chairs) Sustaining work hours without decrements in productivity. Symposium presented at the 92nd Annual Meeting of the American Psychological Association, Toronto, Canada, August 1984. The authors' mailing address is: Center for Applied Psychological Studies, Old Dominion University, Norfolk, VA 23508-8561. sustained operations (both held in August 1984) and to discuss a number of the most salient methodological problems associated with sustained operations research.

\section{BACKGROUND}

\section{Methodological Development}

From a historical perspective, it appears that much of the initial effort in this area of research has been devoted to developing suitable methodologies for assessing human performance over prolonged periods of time. In the early phases of this research, the requirement to provide continuous measurements of performance during long work shifts presented new and unique problems to the technology of performance assessment. Before researchers could proceed with systematic investigations of the human ability to maintain performance and productivity during sustained work periods, it was necessary to establish the viability of applicable performance assessment methodologies. Thus, early researchers in this area invested a considerable amount of effort in the development and evaluation of various approaches to the assessment of sustained performance. The nature and extent of this effort are most clearly demonstrated by the 1967 special issue of Human Factors, which was devoted to discussions of the methodological problems involved in assessing complex performances (Chiles, 1967). The papers contained in that special issue reflected the existence of three basic approaches to the study of human performance. Since these three broad categories of performance measurement procedures are still applicable today, it is instructive to identify them briefly. More detailed comparisons among the three approaches are provided by Alluisi (1967).

The three types of performance measurement methodologies can be represented as occupying different relative positions along a continuum that represents a tradeoff in terms of the degree of fidelity, face validity, and costs and the degree of experimental control, ease of measurement, and breadth of applicability. The first of these approaches involves the use of full-scale simulations (see 
Grodsky, 1967). To the extent that the representations are faithful, simulation techniques have high face validity and direct generalizability to the simulated conditions. However, they present formidable problems with respect to the meaningful measurement of performance, the generalizability of results beyond the situation that is simulated, and the cost of the initial simulation. Nevertheless, simulations of specific hardware systems have been employed successfully in the study of sustained performance (e.g., Francesconi, 1978; Heslegrave \& Angus, 1983; Krueger, Armstrong, \& Cisco, 1980).

We would include within this categorization those studies involving efforts to simulate actual operational conditions in field tests of sustained military operations (e.g., Lees, Stone, Jones, Kimball, \& Anderson, 1979; Pleban \& Thomas, 1985). Although certain aspects of combat cannot be simulated, several studies have provided rather realistic tests of military unit capabilities to conduct sustained operations. "Operation Early Call" (Haslam, 1978, 1985a, 1985b; Haslam, Allnutt, Worsley, Dunn, Abraham, Few, Labuc, \& Lawrence, 1977) is an excellent example of such investigations. Results from those studies are representative of studies of this type (see also Bugge, Opstad, \& Magnus, 1979, and Haslam, 1981) in that subjects in the field tend to indicate surprising resistance to the effects of sleep loss during sustained operations, particularly for physical tasks. It should be noted, however, that these results are based on measurements of individual rather than unit performance, and that individual and unit results are not always consistent.

For example, Krueger, Armstrong, and Cisco (1980, 1985) required two-man crews to fly a helicopter simulator for $14 \mathrm{~h}$ a day over a week-long trial of sustained operations. Their results indicate that although performances were satisfactory most of the time, the crews differed significantly with respect to the precision of their flight performances. In a study of the performance of tank crews during a 48-h simulated combat field exercise, Ainsworth and Bishop (1971) found that passive surveillance and driving performances were significantly degraded, but that communication and maintenance functions were not similarly affected. Although not conclusive, these results serve to support the suggestion that it is possible that some subjects may work harder in order to compensate for temporary degradations in the performances of their crewmates, thereby minimizing decrements in crew performance. It is possible, however, that in some situations a small, nonsignificant decrement in individual performance will result in critical disruptions in the operation of the crew. Thus, it seems advisable in studies of this type to begin to include measures of both individual and unit performances.

In contrast to the type of assessments provided by simulation techniques, research based on the specific-test technique measures the performance of subjects on a battery of individual laboratory tasks designed to test specific narrowly defined performance abilities (see Fleishman, 1967). In research of this type, tasks should be selected on the basis of a taxonomy of the behavioral dimensions involved in operational performance. If this is done properly, the selected tasks will provide performance assessments that have rather broad applicability to jobs that involve the tested abilities. Unfortunately, these specific tasks (e.g., logical reasoning, serial subtraction, reaction time of various types) too often bear little resemblance to operational jobs. This results in low face validity and motivational characteristics that make it difficult, at best, to generalize from these tasks to performance in the real world.

Nevertheless, specific task techniques have been used widely in the study of sustained operations. Dinges, Orne, and Orne's (1985) study of postnap performances best exemplifies how performance is assessed by using specific tasks. In another example of this type of research, Webb (1985) listed 16 subjective and objective measures of the effects of extended performance (see also Frazier, Benigus, Every, \& Parker, 1971, and Rosa, Wheeler, Warm, \& Colligan, 1984). Webb described a series of four laboratory experiments designed to determine (1) whether older inviduals (who are more likely to be assigned to command positions) experience larger performance decrements than younger persons and (2) the optimum schedule for limited rest periods during sustained work. Not too surprisingly, this research indicates that older individuals perform more poorly than younger persons during prolonged periods of performance. On the basis of the work of Monk, Fookson, Kream, Moline, Pollak, and Weitzman (1985), this result might be caused by the fact that older individuals find it more difficult to override their more deeply entrained endogenous circadian systems.

Angus and Heslegrave (1985) used continuous cognitive tasks to measure performance in their simulation of a command environment. They found that if a task is embedded within another (primary) task, it becomes more difficult to maintain performance on that task. This suggests that single-task, specific-test assessments of performance may not be sensitive enough to allow generalization to sustained operations that require operators to perform complex tasks.

The third type of performance assessment methodology is known as the synthetic-work technique (see Alluisi, 1967). As employed by Alluisi and his colleagues, this technique has involved the concurrent measurement of the multiple-task performances of five-person crews of subjects in a synthetic-work situation (Morgan \& Alluisi, 1972). It is intermediate to the simulation and specifictest techniques with respect to the continuum of relative advantages and disadvantages; that is, it is designed to minimize the disadvantages of the other two approaches while maximizing their advantages. Its design features include the measurement of (1) time-shared performances at varying (but realistic) workload levels, (2) team performances that depend upon the coordination and cooperation among crew members, and (3) continuous performance over durations of any specified length. This research represents one of the most systematic laboratory 
assessments of performance during sustained operations (Alluisi, Coates, \& Morgan, 1977; Alluisi \& Morgan, 1982; B. B. Morgan, 1974).

\section{Experimental Investigation}

The second phase of research in this area has been more directly concerned with using one of the identified methodologies for assessing and documenting the effects of sleep loss, continuous work, work-rest schedules, and other temporal, circadian, scheduling, and individual variables that impact upon the human ability to maintain effective performance. Nearly 20 years of this research has produced a vast array of data describing the effects of such variables. Although a summary of these findings is beyond the scope of the current discussion, the reader is referred to the several summaries, reviews, and bibliographies that are available in this area (see Alluisi, 1967, Alluisi \& Morgan, 1982, Horne, 1978, Krueger \& Fagg, 1981, Naitoh \& Townsend, 1970, Thompson, 1983, Webb, 1982, and Woodward \& Nelson, 1974).

Although these variables are still of immediate concern to investigators, additional recent research has turned attention to finding ways to enhance performance during sustained operations by the use of effective sleep scheduling (napping), physical exercise, pharmacological intervention, and other "counterdegradation measures"' (cf. Dinges, Orne, Orne, \& Evans, 1983; McGlynn, Laughlin, \& Rowe, 1979; W. E. Morgan, 1984; Naitoh, 1981; Nicholson, 1983; Webb \& Agnew, 1973). The initial thrust for this applied research direction was provided primarily by the military's realization that the technological capability for prolonged, high-intensity combat necessitates more or less continuous human performance with little opportunity for recuperative rest or sleep.

\section{Practical Application}

The current emphasis on the applied aspect of research has resulted in the development of practical guidelines for the planning of continuous military operations (see Department of the Army, 1983, and Woodward \& Nelson, 1974), efforts to incorporate the available findings into a model for predicting the "performance effectiveness of combat troops" in continuous operations (i.e., the PERFECT model; see Siegel, Pfeiffer, Kopstein, Wolf, \& Ozkaptan, 1980, and Siegel, Taylor, Shuler, \& Pfeiffer, 1979), and recommendations for the management of sleep during continuous operations (W. E. Morgan, 1984; Naitoh, Englund, \& Ryman, 1983). These efforts represent important contributions to the development and enhancement of sustained performance capabilities.

\section{GENERAL OBSERVATIONS}

(1) The military is the most urgent user of research in the area of sustained operations, and the military's concern for sustained performance during combat has stimulated much of the research. This is illustrated by the reports of Hegge (1984) and Haslam (1985a, 1985b), which address the issues of performance requirements and human capabilities as they apply to continuous military operations. Hegge $(1982,1984)$ pointed out that the problems of sustained performance are crucial to the success of military forces on the "battlefield of the future." He calls for studies of: the efficacy of fragmented sleep taken at different times within the circadian cycle; the physiological and behavioral responses to sustained operations via an interdisciplinary, integrated approach; the realistic aspects of operational continuous operations situations; and the efficacy of behavioral and physiological interventions within sustained operations. The research program described by Monk et al. (1985), which is dedicated to the study of circadian effects during sustained operations in the laboratory, illustrates one effort in this direction. It also indicates some of the difficulties inherent in such research.

(2) Most research in this area has been generated by the military, and many of the relevant data have been collected from military subjects performing military-type tasks under militarily relevant conditions of sustained operations. This observation is important because answers obtained in research depend in part upon the questions asked. In this case, military researchers usually ask a particular set of questions that are most pertinent to military interests. Yet, to the extent that other concerns (e.g., those of fire and rescue personnel, industrial watchkeeping, etc.) are not represented by this research, the generalizability of results is limited.

This observation is best illustrated by the studies of Haslam (1985a, 1985b), who conducted three studies primarily concerned with the performance effects of sustained military operations. In one study, subjects were tested only at 0430 and $0930 \mathrm{~h}$ daily, rather than continuously during the sustained operation. Much of their awake time was filled with game playing. The most significant finding was that subjects who were allowed to sleep for $4 \mathrm{~h}$ during each 24-h period experienced no significant performance decrements in a 6-day $(152-\mathrm{h})$ trial. However, one must question the extent to which the result is determined by the selection of this intermittent testing schedule. More frequent demands for, and assessments of, performance might have resulted in greater sensitivity to the potential effects of sustained operations, and certainly would have yielded a methodology that more closely resembles the performance requirements of "real" combat situations.

(3) Questions concerning the ability to sustain performance during prolonged work hours are as important to private industry as they are to the military establishment. This is best illustrated by the implications of the studies by Price (1984) and Schneider and Kelly (1984). Price (1984) reported on several major airline accidents that appeared to have had a causal link with crew and/or air traffic controller sustained operations. He calls for "scientific" investigations of the extent to which fatigue and sleep loss might contribute to airline accidents. Schneider and Kelly (1984) conducted a model human reliability as- 
sessment of human operators in a nuclear generating station. They assessed the probability of errors and personnel accidents for 8- and 12-h shifts and determined that there would be a $70 \%$ increase in the probability of a public nuclear accident if $12-\mathrm{h}$ shifts were used. The extreme social implications of the threat of such an accident obviously prohibit the operational testing of these results. However, the results of these two studies clearly illustrate how important knowledge concerning the human ability to perform during sustained operations is to the industrial sector.

(4) A major objective of much of the recent research in this area is the enhancement of human performance during sustained operations. Several studies have been directly concerned with developing ways to sustain effective performance over longer durations or to increase the level of performance for specified intervals of time. An example of research that attempts to enhance sustained performances is provided by Dinges et al. (1985). These researchers have been involved in a program designed to assess the efficacy of napping as a tool to enhance sustained performance (see also Haslam, 1978, 1981, 1985a, 1985b, and Naitoh et al., 1983). Although napping appears to be an effective method for preventing performance deterioration during sustained operations, it also produces a period of confusion and performance decrement immediately upon awakening.

Although their study was not designed specifically to investigate ways to enhance performance during sustained operations, Englund, Ryman, Naitoh, and Hodgdon (1985) found that physical activity may serve to reduce the effects of prolonged cognitive work. They found that napping, however, did not improve performance on their cognitive tasks. Further research is needed to determine when and how much increased physical activity provides a beneficial rather than detrimental addition to the overall workload of a sustained operation.

Nicholson (1983) suggested that it is necessary to investigate the effects of pharmacological methods of sustaining performance over time. His research suggested that both over-the-counter and prescription preparations may actually inhibit performance rather than enhance it, especially if they are taken over prolonged periods of time without allowance for the potential buildup of the drug in the bloodstream. The high reliance of many individuals on caffeine and nicotine, as well as on over-the-counter and prescription medicines, makes it all the more important to fully examine the potential impact of such substances on the ability to conduct continuous operations. Although a thorough discussion of this topic is beyond the scope or purpose of this paper, suffice it to say that the development of methods to enhance sustained performance is a fruitful area for future research.

(5) Current research is concerned not only with enhancing sustained performance. Some efforts are also concerned with predicting individual differences in the ability to sustain performance for long periods of time. Some success has already been achieved with respect to select- ing shift workers (see Folkard, Monk, \& Lobban, 1979), and it is reasonable to assume that future research will provide a basis for selecting individuals in terms of their ability to sustain effective levels of performance.

This line of research can be illustrated by the work of Stern, Strock, and Goldstein (1984), who have been evaluating the use of an oculometer to observe the physiological events that surround missed signals. They have found that missed signals are more likely to occur when signal presentation coincides with a variety of physiological events that appear to identify lapses in attention. This type of research is important because it has the potential to provide a basis for predicting performance during sustained operations using psychophysiological measures. It might also be assumed that this methodology will be sensitive to the differences in arousal that may occur at different points during the circadian cycle, with different workloads, or with other temporal, scheduling, and individual variables. Studies of individual differences in sustained performance and their correlates are clearly needed in order to establish a basis for selecting the most capable performers.

(6) A number of different methodologies have been applied successfully to the study of sustained performance. For example, Haslam (1985a, 1985b), as well as Dinges et al. (1985), have used specific tests to assess performance capabilities; Tepas, Armstrong, Carlson, Duchon, Gersten, and Lezotte (1984) employed questionnaires to document workers' responses to longer work hours; Schneider and Kelly (1984) made reliability analyses to determine the likelihood that longer work hours would result in a major accident; Stern et al. (1984) applied a physiological measurement procedure to study lapses in attention; and Mullaney, Fleck, Okudaira, and Kripke (1985) developed a computerized specific-task battery capable of assessing teams. Although each of these methodologies has been applied to address slightly different questions, it appears that the greatest payoff in sustained performance research could be achieved through the joint application of several such methodologies.

\section{SUMMARY AND CONCLUSIONS}

It is possible to trace a historical trend. This trend began with efforts to establish the applicability of various research methodologies to the investigation of sustained operations; it expanded in many directions as researchers attempted to document human capabilities to perform over prolonged periods of time in various conditions; and the trend recently resulted in the development of preliminary guidelines and recommendations for optimizing performance during sustained operations. It is interesting to note that the research reported in this special section also may be discussed in relation to these three phases of effort. For example, the papers by Tepas et al. (1984) and Stern et al. (1984) discuss the applicability of questionnaire and physiological measurement techniques, respectively, to the study of sustained operations, and the reports by Has- 
lam (1985a, 1985b), Hegge (1984), Pleban and Thomas (1985), and Schneider and Kelly (1984) address the performance requirements and human capabilities that impact sustained operations. Lastly, the work reported by Dinges et al. (1985), as well as that by Stern et al. (1984), deals with procedures for enhancing performance during sustained performance.

Examination of these studies gives rise to several methodological issues that have important implications for research on sustained performance. A prime consideration is the selection of a performance assessment methodology. Each method predisposes results toward an outcome that may, by virtue of the questions asked, influence the conclusions reached on the basis of that research. Along with choosing a viable assessment methodology, it is important to consider the relative "continuousness" of the assessment procedures. The timing and frequency of the assessments are important variables in such research. Also included are issues raised by Hegge (1984) in reference to military needs during sustained operations but that actually apply to all research on the topic.

Finally, because sustained operations capabilities are important and salient to both the military and private sectors, researchers must be challenged to continue to study methodologies that may be used to enhance human capabilities under a variety of sustained performance conditions. Such applied research eventually may make it possible to select individuals who will perform at higher levels during sustained operations. In turn, this would make it possible to significantly enhance the capability to sustain work hours without decrements in performance and productivity.

On the basis of the historical evidence of methodological problems in assessing sustained human performance and the gaps evidenced in the current literature, it appears that research in this area would benefit from the conduct of a meta-analysis that would combine studies from a variety of disciplines and approaches. In addition, there is a need for interdisciplinary, integrated investigations of (1) the ability to perform continuously (or nearly so) for periods that are longer than those tested in most previous research (e.g., up to $72 \mathrm{~h}$ ), (2) the ability to maintain performance throughout several successive continuouswork/rest cycles, when the rest periods provide insufficient sleep for the full recovery of performance, (3) the interactive effects of cognitive and physical work in continuous operations and the influence of physical fitness on sustained cognitive and physical performances, (4) the prediction of individual differences in the ability to maintain performance for extended periods of time and the utility of selecting sustained performers on the basis of those differences, and (5) the relative effectiveness of methods (e.g., napping, physical activity, biofeedback, etc.) to enhance performance during continuous operations across a variety of situations. Future research and development in these areas are seen as critical to the enhancement of our ability to sustain work hours without decrements in performance and productivity.

\section{REFERENCES}

AINSWORTH, L. L., \& Bishop, H. P. (1971). The effects of a 48-hour period of sustained field activity on tank crew performance (Hum RRO Tech. Rep. No. 71-16). Alexandria, VA: Human Resources Research Organization.

AlLUIS, E. A. (1967). Methodology in the use of synthetic tasks to assess complex performance. Human Factors, 9, 375-384.

Alluisi, E. A., Coates, G. D., \& Morgan, B. B., JR. (1977). Effects of temporal stressors on vigilance and information processing. In R. R. Mackie (Ed.), Vigilance: Theory, operational performance, and physiological correlates. New York: Plenum Press.

Alluisi, E. A., \& Morgan, B. B., JR. (1982). Temporal factors in human performance and productivity. In E. A. Alluisi \& E. A. Fleishman (Eds.), Human performance and productivity: Vol. 1. Stress and human effectiveness (pp. 165-248). Hillsdale, NJ: Erlbaum.

Angus, R. G., \& Heslegrave, R. J. (1985). Effects of sleep loss on sustained cognitive performance during a command and control simulation. Behavior Research Methods, Instruments, \& Computers, 17, 55-67.

Bugge, J. F., Opstad, P. K. , \& Magnus, P. M. (1979). Changes in the circadian rhythm of performance and mood in healthy young men exposed to prolonged, heavy physical work, sleep deprivation and caloric deprivation. Aviation, Space, and Environmental Medicine, 50, 663-668.

Chiles, W. D. (1967). Methodology in the assessment of complex performance. Human Factors, 9, 325-392.

DePARTMENT OF THE ARMY. (1983, December). Soldier performance in continuous operations: Field manual (Report No. FM 22-9). Washington, DC: Headquarters Department of the Army.

Dinges, D. F., Orne, M. T., \& Orne, E. C. (1985). Assessing performance upon abrupt awakening from naps during quasi-continuous operations. Behavior Research Methods, Instruments, \& Computers, $17,37-45$.

Dinges, D. F., Orne, M. T., Orne, E. C., \& Evans, F. J. (1983). Voluntary self-control of sleep to facilitate quasi-continuous performance. Frederick, MD: Fort Detrick, U.S. Army Medical Research and Development Command.

Englund, C. E., Ryman, D. H., Naitoh, P., \& Hodgdon, J. A. (1985). Cognitive performance during successive sustained physical work episodes. Behavior Research Methods, Instruments, \& Computers, 17, 75-85.

Fleishman, E. A. (1967). Performance assessment based on an empirically derived task taxonomy. Human Factors, 9, 349-366.

FolKard, S., MONK, T. H., \& LobBan, M. C. (1979). Towards a predictive test of adjustment to shift work. Ergonomics, 22, 79-91.

FRANCESCONI, R. P. (1978). Sleep deprivation and sustained operations: Effects on indices of stress. Natick, MA: Army Research Institute of Environmental Medicine.

Frazjer, T. W., Benigus, V. A., Every, M. G., \& Parker, J. F., JR. (1971). Effects of 72-hour partial sleep deprivation on human behavioral and physiological response measures. Falls Church, VA: Biotechnology, Inc.

Glickman, A. S., \& Brown, Z. H. (1974). Changing schedules of work: Patterns and implications. Washington, DC: W. E. Upjohn Institute for Employment Research.

Grodsky, M. A. (1967). The use of full scale mission simulation for the assessment of complex operator performance. Human Factors, 9, 341-348.

Haslam, D. R. (1978). The effect of continuous operations upon the military performance of the infantryman (exercise "Early Call" II) (Report APRE No. 4/78). Farnborough, England: Army Personnel Research Establishment.

HASLAM, D. R. (1981). The military performance of soldiers in continuous operations: Exercises Early Call I and II. In L. C. Johnson, D. I. Tepas, W. P. Colquhoun, \& M. Colligan (Eds.), Biological rhythms, sleep and shift work. New York: Spectrum.

HASLAM, D. R. (1985a). Sleep deprivation and naps. Behavior Research Methods, Instruments, \& Computers, 17, 46-54.

HASLAM, D. R. (1985b). Sustained operations and military performance. 
Behavior Research Methods, Instruments, \& Computers, 17, $90-95$.

Haslam, D. R., Allnutt, M. F., Worsley, D. E., Dunn, D., Abraham, D., Few, J., Labuc, S., \& Lawrence, D. J. (1977). The effect of continuous operations upon the military performance of the infantryman (exercise "Early Call") (Report APRE No. 2/77). Farnborough, England: Army Personnel Research Establishment.

HEGGE, F. W. (1982). The future battlefield: Human dimensions and implications for doctrine and research. Washington, DC: Walter Reed Army Institute of Research.

HEGGE, F. W. (1984, August). Evolution in the psychological demands of modern warfare. In C. E. Englund \& G. P. Krueger (Co-chairs), Sustaining work hours without decrements in productivity. Symposium presented at the meeting of the American Psychological Association, Toronto.

Heslegrave, R. J., \& ANGus, R. G. (1983). Sleep loss and continuous work [Report No. DS/A/OR. (83) 170]. In Proceedings of the 24th Defense Research Group Seminar: The Human as a Limiting Element in Military Systems. Toronto: NATO Defense Research Section.

HoRNe, J. A. (1978). A review of the biological effects of total sleep deprivation in man. Biological Psychology, 7, 55-102.

Kossonis, M. D., KoHLER, R. F. (1947). Hours of work and output (U.S. Department of Labor, Bureau of Labor Statistics Bulletin No. 917). Washington, DC: U.S. Government Printing Office.

Krueger, G. P., Armstrong, R. N., \& Cisco, R. R. (1980, May). Aviator performance in week-long extended flight operations in a helicopter simulator. (Report No. NATO-AGARD CP-286). In R. Auffret (Ed.), Session A: Aircrew safety and survivability conference proceedings. London: Technical Editing and Reproduction, Ltd.

Krueger, G. P., Armstrong, R. N., \& Cisco, R. R. (1985). Aviator performance in a week-long extended flight operations in a helicopter simulator. Behavior Research Methods, Instruments, \& Computers, 17, 68-74.

KRUEGER, G. P., \& FAG, J. N. (1981, January). Aeromedical factors in aviator fatigue, crew work/rest schedules and extended flight operations: An annotated bibliography (USAARL Report No. 81-1). Fort Rucker, AL: U.S. Army Aeromedical Research Laboratory.

Lees, M. A., Stone, L. W., Jones, H. D., Kimball, K. A., \& ANDERSON, D. B. (1979). The measurement of man-helicopter performance as a function of extended flight requirements and aviator fatigue (USAARL Report No. 79-12). Fort Rucker, AL: U.S. Army Aeromedical Research Laboratory.

McGlynn, G. H., Laughlin, N. T., \& Rowe, V. (1979). The effect of increasing levels of exercise on mental performance. Ergonomics, 22, 407-414.

Monk, T. H., Fookson, J. E., Kream, J., Moline, M. L., Pollack, C. P., \& Weitzman, M. B. (1985). Circadian factors during sustained performance: Background and methodology. Behavior Research Methods, Instruments, \& Computers, 17, 19-26.

Morgan, B. B., JR. (1974). Effects of continuous work and sleep loss in the reduction and recovery of work efficiency. American Industrial Hygiene Association Journal, 35, 13-20.

Morgan, B. B., JR., \& Alluisi, E. A. (1972). Synthetic work: Methodology for assessment of human performance. Perceptual and Motor Skills, 33, 835-845.

MORGAN, W. E. (1984). A study on the management of sleep and stress in continuous operations (Report No. SB3-83-14230). Fort Benjamin Harrison, IN: U.S. Army Training and Doctrine Command.

Mullaney, D. J., Fleck, P. A., Okudaira, N., \& Kripke, D. F. (1985). An automated system for administering continuous workload and for measuring sustained continuous performance. Behavior Research Methods, Instruments, \& Computers, 17, 16-18.

NaIToH, P. (1981). Circadian cycles and restorative power of naps. In L. C. Johnson, D. F. Tepas, W. P. Colquhoun, \& M. J. Colligan (Eds.), Biological rhythms, sleep and shift work (pp. 553-580). New York: Spectrum.
Nattoh, P., Englund, C., \& Ryman, D. H. (1983). Extending human effectiveness during continued operations through sleep management (Report No. 83-13). San Diego, CA: Naval Health Research Center.

NaIroH, P., \& Townsend, R. E. (1970). The role of sleep deprivation research. Human Factors, 12, 575-585.

Nicholson, A. L. (1983, April). Hypnotics and air operations. Paper presented at the Aerospace Medical Panel Specialists' Meeting, Paris.

Pleban, R. J., \& Thomas, D. A. (1985). Physical fitness as a moderator of cognitive work capacity and fatigue onset under sustained combat-like operations. Behavior Research Methods, Instruments, \& Computers, 17, 86-89.

Price, W. J. (1984, August). Sleep loss, reaction time, and airline crashes. Paper presented at the Canadian Defence and Civil Institute of Environmental Medicine SUSOPS Meeting, Toronto.

Rosa, R. R., Wheeler, D. D., WARM, J. S., \& Colligan, M. J. (1984, August). Extended workdays: Effects on performance and ratings of fatigue and alertness. Paper presented at the Canadian Defence and Civil Institute of Environmental Medicine SUSOPS Meeting, Toronto.

Schneider, M. F., \& Kelly, R. J. (1984, August). 12-hour shift effects on human performance at nuclear generating stations. In C. E. Englund \& G. P. Krueger (Co-chairs), Sustaining work hours without decrements in productivity. Symposium presented at the meeting of the American Psychological Association, Toronto.

Siegel, A. I., Pfeiffer, M. G., Kopstein, G., Wolf, S. S., \& OzKAPTAN, H. (1980). Human performance in continuous operations (Vol. 3). Alexandria, VA: U.S. Army Institute for the Behavioral and Social Sciences.

Siegel, A. I., TA ylor, S. E., Shuler, L., \& Pfeiffer, M. G. (1979). Human performance in continuous operation guidelines. Alexandria, VA: U.S. Army Institute for the Behavioral and Social Sciences.

Stern, J. A., Strock, B. D., \& Goldstein, R. (1984, August). Application of psychophysiology to the prediction of performance decrements. In C. E. Englund \& G. P. Krueger (Co-chairs), Sustaining work hours without decrements in productivity. Symposium presented at the meeting of the American Psychological Association, Toronto.

Tepas, D. I., Armstrong, D. R., Carlson, M. L., Duchon, J. C., Gersten, A., \& Lezotte, D. V. (1984, August). Changing industry to continuous operations: Different strokes for different plants. In C. E. Englund \& G. P. Krueger (Co-chairs), Sustaining work hours without decrements in productivity. Symposium presented at the meeting of the American Psychological Association, Toronto.

ThOMPSON, H. I. (1983). Physical fitness as a moderator of cognitive degradation during sleep deprivation. Fort Leavenworth, KS: U.S. Army Command and General Staff College.

WEBB, W. B. (1982). Biological hythms, sleep, and performance. New York: Wiley.

WEBB, W. B. (1985). Experiments on extended performance: Repetition, age, and limited sleep periods. Behavior Research Methods, Instruments, \& Computers, 17, 27-36.

WEBB, W. B., AGNEW, H. W., JR. (1973). Effects on performance of high and low energy-expenditure during sleep deprivation. Perceptual and Motor Skills, 37, 511-514.

WOODWARD, D. P., \& NELSON, P. D. (1974). A user oriented review of the literature on the effects of sleep loss, work-rest schedules, and recovery on performance. Washington, DC: Office of Naval Research.

\section{NOTE}

1. Observations concerning methodological issues in this research are drawn from a discussion of presentations made at the Sustained Operations Workshop held at the Canadian Defence Civil Institute of Environmental Medicine (DCIEM), Toronto (August 23, 1984), and the American Psychological Association Symposium on Sustained Work, also held in Toronto (August 25, 1984) 